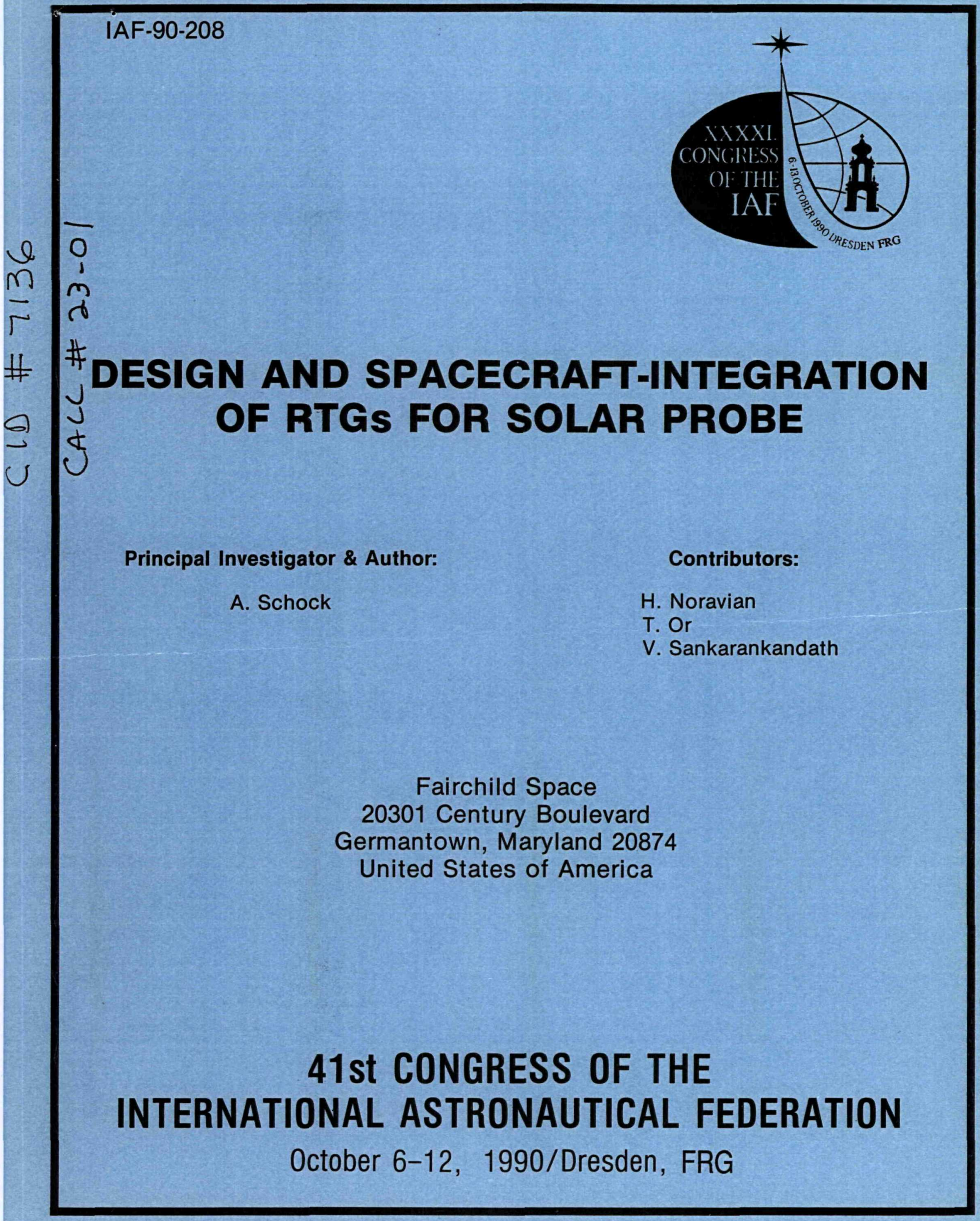

For permission to copy or republish, contact the International Astronautical Federation, 3-5, Rue Mario-Nikis, 75015 Paris, France 


\section{DISCLAIMER}

This report was prepared as an account of work sponsored by an agency of the United States Government. Neither the United States Government nor any agency Thereof, nor any of their employees, makes any warranty, express or implied, or assumes any legal liability or responsibility for the accuracy, completeness, or usefulness of any information, apparatus, product, or process disclosed, or represents that its use would not infringe privately owned rights. Reference herein to any specific commercial product, process, or service by trade name, trademark, manufacturer, or otherwise does not necessarily constitute or imply its endorsement, recommendation, or favoring by the United States Government or any agency thereof. The views and opinions of authors expressed herein do not necessarily state or reflect those of the United States Government or any agency thereof. 


\section{DISCLAIMER}

Portions of this document may be illegible in electronic image products. Images are produced from the best available original document. 
IAF-90-208

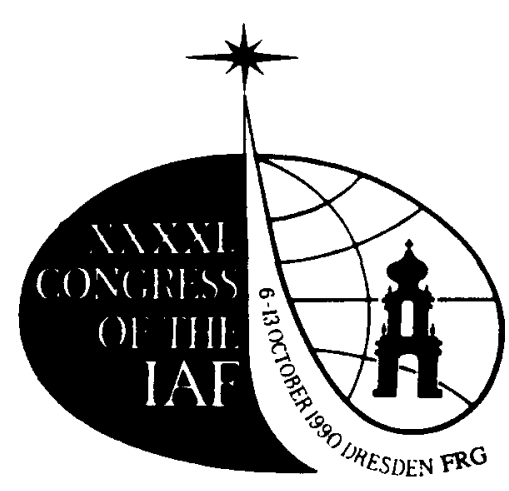

\section{DESIGN AND SPACECRAFT-INTEGRATION OF RTGS FOR SOLAR PROBE}

Principal Investigator \& Author:
A. Schock
H. Noravian
T. Or
V. Sankarankandath

Contributors:

Fairchild Space 20301 Century Boulevard

Germantown, Maryland 20874

United States of America

\section{1st CONGRESS OF THE INTERNATIONAL ASTRONAUTICAL FEDERATION October 6-12, 1990/Dresden, FRG}




\title{
DESIGN AND SPACECRAFT-INTEGRATION OF RTGs FOR SOLAR PROBE
}

\author{
A. Schock (Author and Principal Investigator) \\ H. Noravian, T. Or, V. Sankarankandath (Contributors) \\ Fairchild Space \\ Germantown, Maryland 20874 U.S.A.
}

\begin{abstract}
The paper describes the design and analysis of Radioisotope Thermoelectric Generators integrated with JPL's planned Solar Probe spacecraft. The principal purpose of the Solar probe mission is to explore the solar corona by performing in-situ measurements at distances as close as four solar radil or $0.02 \mathrm{AU}$ from the sun. This proximity to the sun imposes some unusual design constraints on the RTG and on its integration with the spacecraft, principally with respect to dissipation of the generator's waste heat to space. A number of schemes for achieving this without excessive performance penalties were examined, and the preferred schemes were analyzed in detail. Since these entail obstructed and highly unsymmetrical heat rejection paths, they required development of a novel analytical approach and computer code for performing coupled thermal and electrical analyses of RTGs with axial and circumferential temperature, current, and voltage variations. The code was validated against measured test data of unobstructed RTGs, and was used for the detailed analysis of highly obstructed RTGs for the Solar Probe mission. The results demonstrated that the obstructions result In significant performance penalties for the case of the standard GPHS-RTG design. Modifications of that design to reduce those penalties are under investigation. Finally, the paper describes a simple empirical method for predicting the combined effect of fuel decay and thermoelectric degradation on the RTG's power output, and applies that method to predict the long-term power profile of the obstructed Solar Probe RTGs. The results indicate that the existing GPHS-RTG design, even without modifications, can meet the JPL-prescribed EOM power requirement.
\end{abstract}

\section{INTRODUCTION}

The paper describes the design, analysis, and spacecraft integration of Radioisotope Thermoelectric Generators (RTGs) to power the Solar Probe under study at NASA's Jet Propulsion Laboratory (JPL). In response to a request for assistance from NASA and JPL, the US Department of Energy's Office of Special Applications commissioned Fairchild Space Company to carry out an RTG design study for that mission, including the RTGs' integration with the spacecraft.
The Solar Probe mission [1] is designed to explore and resolve the fundamental nature of the solar corona. To do so, the probe will perform in-situ measurements at distances as close as four solar radii or $0.02 \mathrm{AU}$ from the sun. The region of the inner heliosphere, from 4 to 65 solar radii, remains the last major unprobed region of our solar system. Its exploration is crucial for understanding the physics of the solar corona and of many fundamental astrophysical processes. In-situ measurements are needed because of the proximity of the low-brightness corona to the much brighter photosphere. Scientific objectives of the Solar Probe mission include measurement of the density, velocity, and composition of the thermal solar wind plasma, and of the magnetic fields, plasma waves, and energetic particles present in this unexplored region of the heliosphere.

To make it possible to reach a solar polar orbit having a perihelion of $0.02 \mathrm{AU}$ with available boosters, it is planned to employ gravity-assist flybys of both the Earth and Jupiter. The Jupiter gravity assist will be used to lift the spacecraft out of the ecliptic plane into the polar plane, as illustrated in Figure 1. The figure depicts a JPL-generated mission plan calling for a 1998 launch and two solar flybys, the first in 2003 and the second in 2007. Scientific observations will be made throughout the mission, not just near the two perihelia. JPL specified a power output of at least 430 watts(e), not just at solar encounter but throughout the 9-year mission.

Figure 1. Solar Probe Trajectory and Schedule

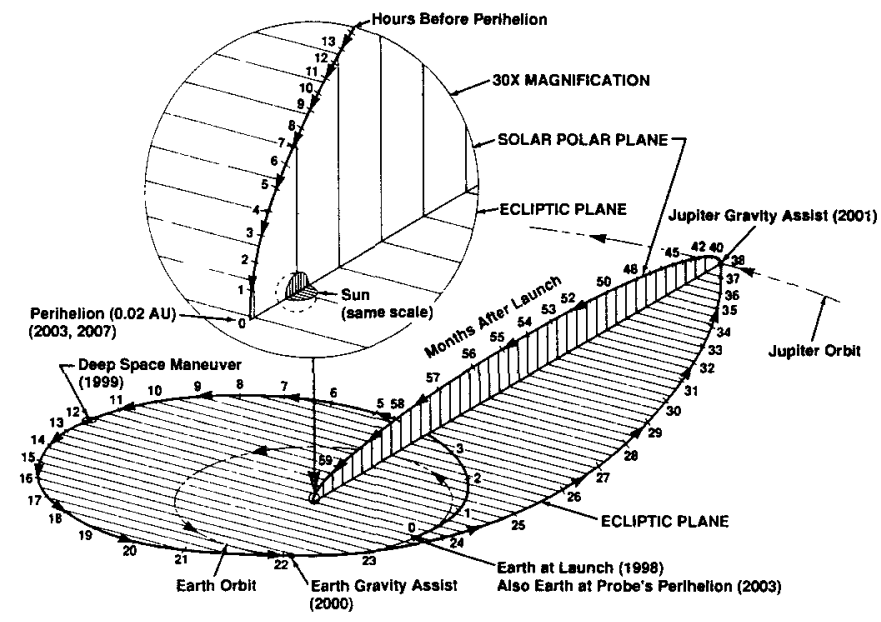


The JPL study team concluded that the mission does not lend itself to solar power, because the solar distance varies from $5 \mathrm{AU}$ at Jupiter to $0.02 \mathrm{AU}$ at perihelion, so that the solar intensity varies by a factor of 62,500 . Therefore, they have baselined the use of RTGs for powering the spacecraft. RTGs in this power range have operated reliably for very long periods on previous space missions, such as the Voyager mission to Neptune and beyond.

\section{RTG DESIGN OPTIONS}

The Fairchild study concluded that the Solar Probe power requirements can be met by two RTGs adapted either from the unicouple-based GPHS-RTG design [2] used for the recently launched Galileo mission or from the more advanced multicouple-based Mod-RTG design [3] under development by DOE. The Mod-RTG would yield a lighter and more compact system, but the GPHS-RTG is a very mature design that has been performance-proven and safety-qualified in extended ground and flight tests. Therefore, the GPHS-RTG design was selected for illustrative purposes in the present paper. However, the spacecraft integration concept and analytical approach described would be equally adaptable to the Mod-RTG option.

The $1.15 \mathrm{~m}$-long GPHS-RTG is depicted in Figure 2. It contains a central heat source consisting of a stack of 18 General Purpose Heat Source modules [4]. The heat generated by isotope decay is radiated to an array of 576 thermoelectric unicouples which are bolted to the RTG's cylindrical housing. The unicouples, shown in Figure 3, convert part of the heat to electricity, and reject the balance to the finned RTG housing, for radiation to space.

Figure 2. GPHS RTG

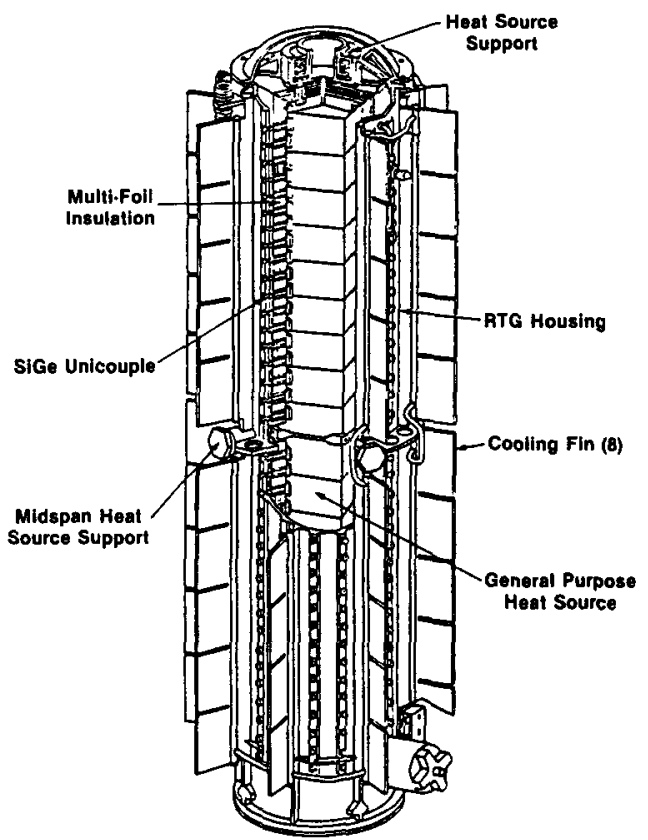

Figure 3. Unicouple

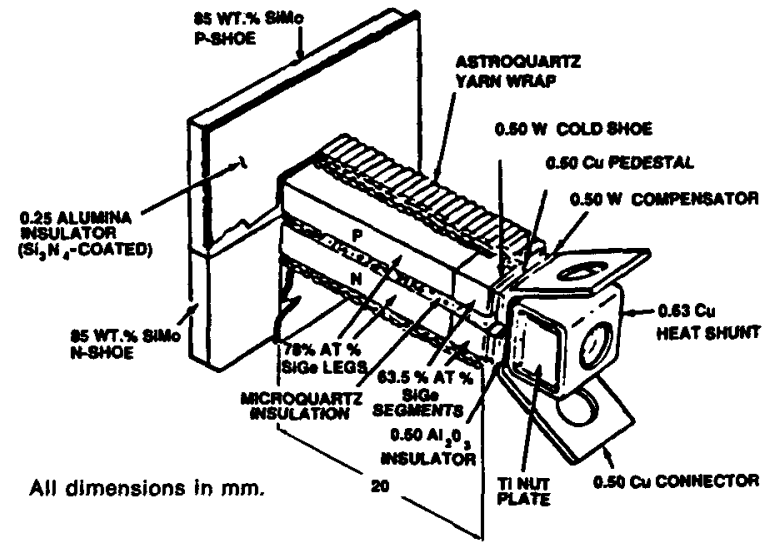

The design constraints on the Solar Probe mission differ from those of previous missions in three respects:

1. Solar Shield: At the $0.02 \mathrm{AU}$ perihelion, the solar intensity is 2500 times as high as in earth orbit. To prevent overheating, the spacecraft will be protected by a conical graphite shield of 4-meter base diameter and 7-meter height as illustrated in Figure 4. Because of the spacecraft's proximity to the sun, the sun acts as a large disk and its rays are far from parallel. As a result, the protected region behind the 4 meter-diameter heat shield is not a cylinder but a cone that is only $7.5 \mathrm{~m}$ long. All the other spacecraft components, including payload appendages and RTG radiators, must fit within the limited volume of that conical umbra.

Figure 4. JPL's Solar Probe Design Concept

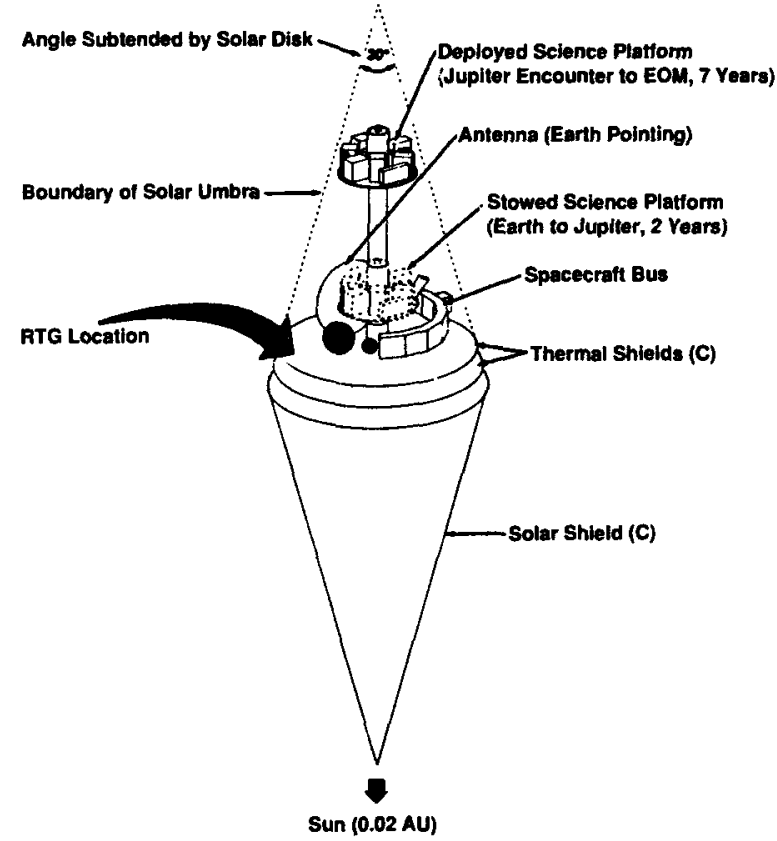


2. Radiation Protection: As in previous RTGpowered spacecraft, the Solar Probe contains radiation-sensitive instrumentation. U.S. space RTGs are fueled with Pu-238, which emits easily stopped alpha particles. But the fuel also generates a very small number of neutrons due to spontaneous fission and $\alpha, \mathrm{n}$ reactions, and it contains minute amounts of Pu-236, whose daughter product $\mathrm{Tl}-208$ emits some energetic gammas. The emitted radiation is generally insignificant, except on missions where the payload includes very sensitive detectors to measure natural background levels. For those missions (e.g., Pioneer, Voyager, Galileo) the RTGs have traditionally been deployed at the end of long booms, to minimize their effect on the detectors. This stratagem cannot be applied to the Solar Probe, because the boom-mounted RTG would not fit within the conical umbra. Therefore, since the RTGs are necessarily near the payload, detailed analysis is required to determine their optimum location and orientation so as to reduce the integrated dose and radiation flux at the deployed science platform to acceptable levels.

3. Heat Rejection: RTGs have relatively low efficiencies, and most of their thermal power ends up as waste heat, to be radiated to space. Most previous RTGs have had an essentially unobstructed view of space. But that is not possible in the Solar Probe. Since everything must be located within the conical umbra, the large solar shield and the payload are necessarily close enough to the RTGs to obstruct their radiators. Moreover, a thermal shield is required between the RTGs and the temperature-sensitive payload, particularly during the first two years of the mission, before the science platform is deployed. Therefore, the solar shield and the payload shield cause severe blockage of the RTG' view of space. Coping with the heat rejection problem is the major challenge to the Solar Probe's RTG designer and system integrator, and is the principal focus of this paper.

Two RTG orientations were investigated: horizontal and oblique. In the horizontal scheme, the two RTGs lie in a plane perpendicular to the spacecraft axis, just behind the heat shield; and in the oblique scheme, the RTGs' long axes point at the deployed science platform, to maximize self-shielding and minimize the payload's radiation flux at solar encounter. Analyses of the radiation doses at the payload's science platiorm were based on measured neutron and gamma dose rates at various radial and axial distances from the GPHS-RTG. The results of the analysis, which are summarized in Table 1 , indicate that the oblique RTG orientation gives somewhat lower doses at the payload, but the difference is not large enough to be decisive. Either orientation appears to be acceptable.
Table 1. Effect of RTG Orientation on Dose at Payload Center

\begin{tabular}{|c|c|c|c|c|}
\hline \multirow{2}{*}{$\begin{array}{l}\text { RTG Orientation } \\
\text { Postition of Sclence Platiorm }\end{array}$} & \multicolumn{2}{|c|}{ Horizontal } & \multicolumn{2}{|c|}{ Oblique } \\
\hline & Stowed & Deployed & Stowed & Deployed \\
\hline $\begin{array}{l}\text { Time in Position, years } \\
\text { Separation distance } ", \mathrm{~m}\end{array}$ & $\begin{array}{r}2 \\
155\end{array}$ & $\begin{array}{r}7 \\
340\end{array}$ & $\begin{array}{r}2 \\
145\end{array}$ & $\begin{array}{r}7 \\
311\end{array}$ \\
\hline Neutron Flux', neutrons $/ \mathrm{cm}^{2}$ sec & 338 & 96 & 383 & 55 \\
\hline $\begin{array}{l}\text { Dose Rate", mrem/hr } \\
\text { Neutrons } \\
\text { Gammas }\end{array}$ & $\begin{array}{l}380 \\
168\end{array}$ & $\begin{array}{r}108 \\
36\end{array}$ & $\begin{array}{l}430 \\
190\end{array}$ & $\begin{array}{l}62 \\
12\end{array}$ \\
\hline $\begin{array}{l}\text { Dose Rate", mrad (Si)/hr } \\
\text { Neutrons } \\
\text { Gammas } \\
\text { Total }\end{array}$ & $\begin{array}{r}42 \\
185 \\
227\end{array}$ & $\begin{array}{l}119 \\
396 \\
515\end{array}$ & $\begin{array}{r}47 \\
\frac{209}{256}\end{array}$ & $\begin{array}{l}068 \\
\frac{132}{200}\end{array}$ \\
\hline $\begin{array}{l}\text { Integrated Dose', rad (Si) } \\
\text { Neutrons } \\
\text { Gammas } \\
\text { Total }\end{array}$ & $\begin{array}{r}73 \\
323 \\
396\end{array}$ & $\begin{array}{r}73 \\
243 \\
316\end{array}$ & $\begin{array}{r}83 \\
366 \\
449\end{array}$ & $\begin{array}{r}42 \\
81 \\
123\end{array}$ \\
\hline TOTAL DOSE & \multicolumn{2}{|c|}{712} & \multicolumn{2}{|c|}{572} \\
\hline
\end{tabular}

\section{HEATPIPE-COOLED RTG}

Figure 5 depicts the case of horizontally oriented RTGs integrated with the Solar Probe spacecraft. It illustrates one of the cooling options investigated; namely, the use of heatpipes wrapped around each RTG's cylindrical housing and delivering its waste heat to a planar, one-sided radiator. This option largely decouples the RTG geometry from the radiator geometry. It would result in uniform cold-junction temperatures and essentially isothermal radiators. Because heatpipe radiators are much lighter than conductive radiators, they would optimize at substantially lower heat rejection temperatures and higher conversion efficiencies than conductive radiators.

Figure 5. Heatpipe - Cooled RTG Option

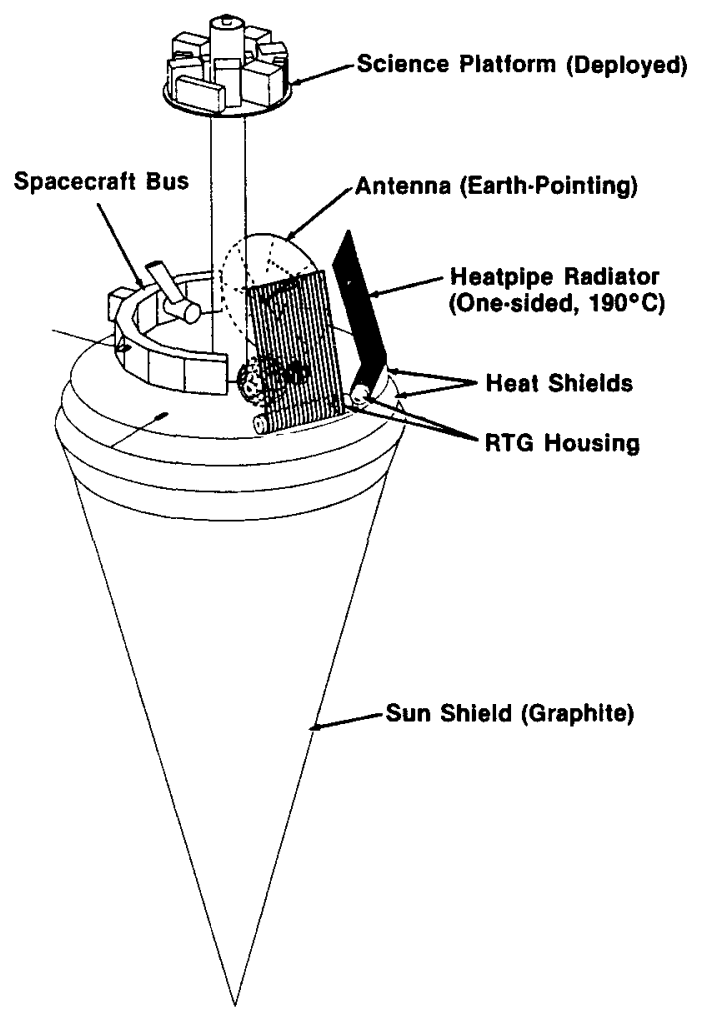


However, these advantages are offset by the fact that in the temperature range of interest the experimental data base on heatpipes is quite limited and very poorly documented. The most successful test the author is aware of was a test of a copper/water heatpipe that ran for 16,000 hours at $190^{\circ} \mathrm{C}$. Performance was stable, but post-test destructive examination revealed internal discoloration, which may be a harbinger of future problems.

Another drawback to the use of copper-water heatpipes (in contrast to alkali metal heatpipes) is that their operation is very sensitive to adverse gravitational effects. Depending on their orientation, this may preclude their operation before and during launch, which would necessitate use of an auxiliary cooling loop. Because of these drawbacks, a heat rejection scheme that does not require heatpipes is considered preferable, provided it does not result in excessive performance penalty.

\section{REFLECTOR-COOLED RTG}

One way of cooling obstructed RTGs without heatpipes is to use a semi-cylindrical or parabolic thermal reflector around the inward-facing side of each RTG. Figure 6 illustrates this concept for horizontally oriented RTGs, and Figure 7 applies it to obliquely oriented generators. Thus, reflector cooling can be applied to either RTG orientation.

Figure 6. Reflector-Cooled RTG, Horizontal Option

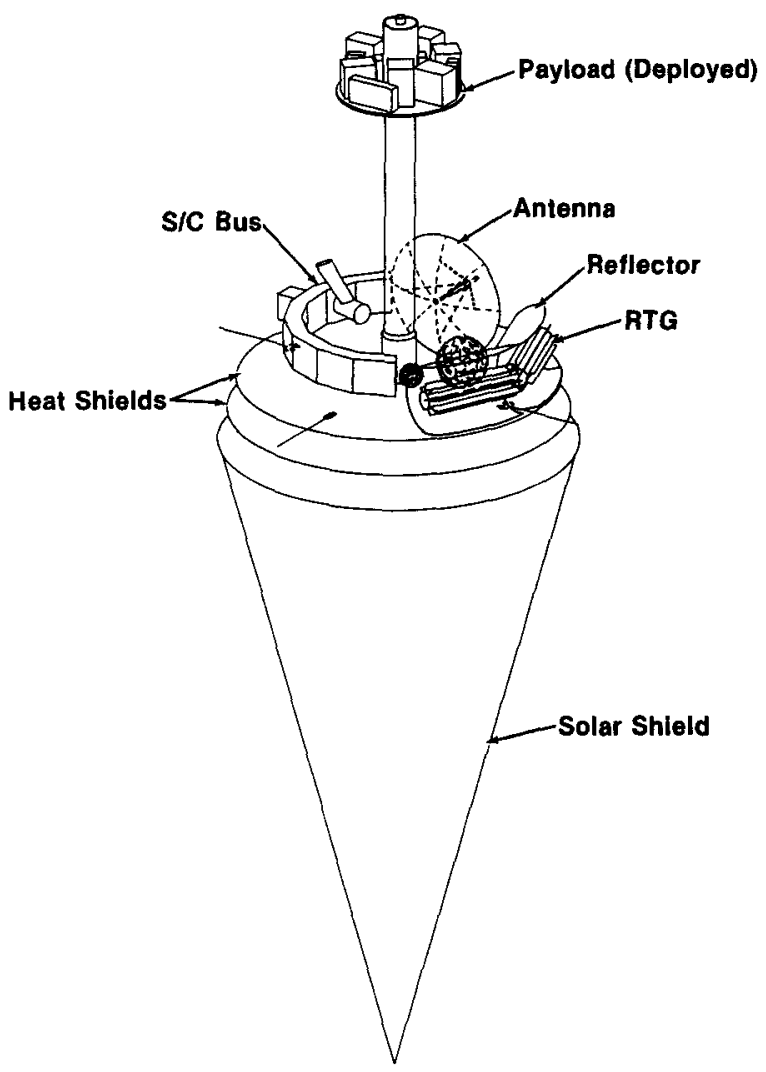

Figure 7. Reflector-Cooled RTG, Oblique Option

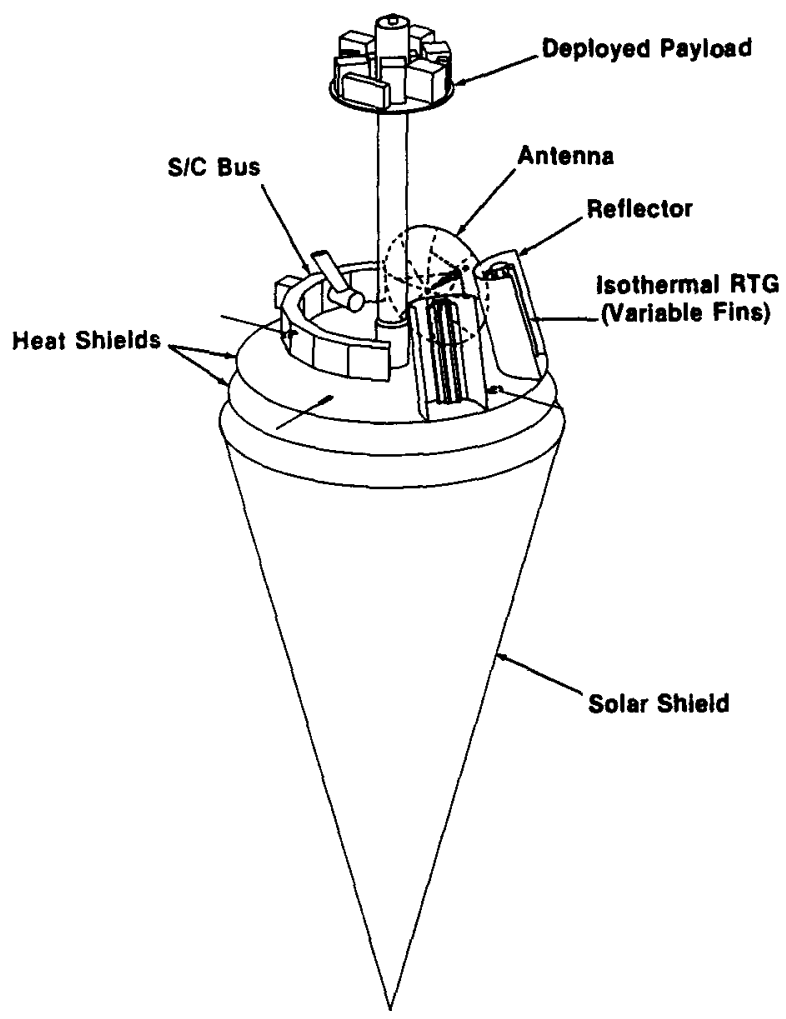

Figure 8 shows two options of a reflector-cooled RTG. To assess the performance of such an arrangement, initial scoping studies employed a simplified analytical model. The simplified model assumed uniform heat input to the inside of the cylindrical RTG housing, and employed a twodimensional $R \theta$ model of the finned RTG housing and the reflector. The RTG had eight fins of trapezoidal cross-section, with $0.060^{\prime \prime}$ fin root, $0.015^{\prime \prime}$ fin tip, and $3^{n}$ root-to-tip length. Detailed radiation-interchange analyses accounting for multiple reflections between the RTG housing, fins, and reflector were performed.

Figure 8. Semi-Cylindrical Reflector Options

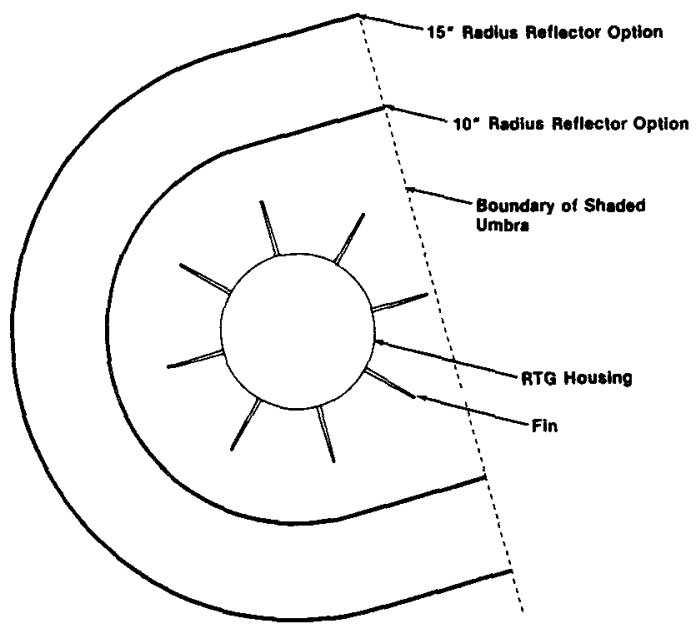


A range of reflector radii and emissivities was analyzed, with the results shown in Tables 2 through 4. Table 2 shows the effect of a semi-cylindrical reflector with a 10-inch radius and an emissivity of 0.85 on the temperature of the GPHS-RTG housing. As shown in the table's right column, the obstructing reflector significantly increases the RTG housing temperatures. For fixed hot-junction temperatures, the resultant increase in cold-junction temperatures would result in a substantial decrease in RTG efficiency and power.

Table 2. Effect of Obstruction by 10"-Radius Reflector on Housing Temperatures of Standard GPHS RTG

\begin{tabular}{lcccc} 
& $\begin{array}{c}\text { Unobstructed } \\
\text { RTG }\end{array}$ & $\begin{array}{c}\text { Reflected } \\
\text { RTG }\end{array}$ & \multicolumn{1}{c}{$\Delta$ T } \\
\cline { 2 - 2 } RTG Housing Temperatures, ${ }^{\circ} \mathrm{C}:$ & & & \\
Max. & 264 & & 382 & 118 \\
Min. & 264 & & 307 & 43 \\
$\Delta T$ & 0 & & 75 &
\end{tabular}

In addition, the table's bottom line shows a circumferential temperature variation of $75^{\circ} \mathrm{C}$, which implies a corresponding variation in optimum couple voltage and current. But all thermoelectric couples in parallel groups must produce the same output voltage, and all groups in series must deliver the same current. Therefore, most of the couples must necessarily operate off-optimum. Thus, a large temperature variation leads to additional degradation of the RTG's efficiency. Clearly, means must be found to reduce the circumferential temperature variation of the obstructed RTG.

One possible way of achieving this is to increase the radius of the semi-cylindrical reflector. Table 3 shows the effect of reflector radius on the RTG housing temperature. Radii of 10, 15, and 25 inches were analyzed. The results show that larger reflector radii do indeed yield significantly lower and more uniform cold-junction temperatures, and therefore higher conversion efficiencies. But larger reflector radii would be more difficult or impossible to accommodate in the limited volume of the conical umbra, without interference with the probe's payload. As a compromise, subsequent analyses assumed an illustrative reflector radius of 15 inches, but it is not yet certain that reflectors of that size can be accommodated on the spacecraft.

Table 3. Effect of Reflector Radius on Temperatures of Reflector and RTG Housing

Reflector Radius, inches $\quad 10$

Reflector Temperatures, ${ }^{\circ} \mathrm{C}$ :

$\begin{array}{llll}\text { Max. } & 329 & 205 & 97 \\ \text { Min. } & 226 & 147 & 73\end{array}$

RTG Housing Temperatures, ${ }^{\circ} \mathrm{C}$ :

$\begin{array}{lrrr}\text { Max. } & 382 & 316 & 277 \\ \text { Min. } & 307 & 284 & 267 \\ \Delta T & 75 & 32 & 10\end{array}$

Table 4 shows the effect of reflector emissivity on the temperatures of the reflector and the RTG housing. Systems with reflector emissivities ranging from 0.10 to 0.85 were analyzed. Surprisingly, it was found that the reflector emissivity has no effect on the RTG housing temperature, and virtually no effect on the reflector temperatures. This is fortuitous, because it eliminates the need for special surface treatments to produce high or low reflector emissivities. Additional analyses examined the effect of specular versus diffuse reflectors, and found essentially the same RTG temperatures for both.

Table 4. Effect of Reflector Emissivity on Temperatures of Reflector and RTG Housing

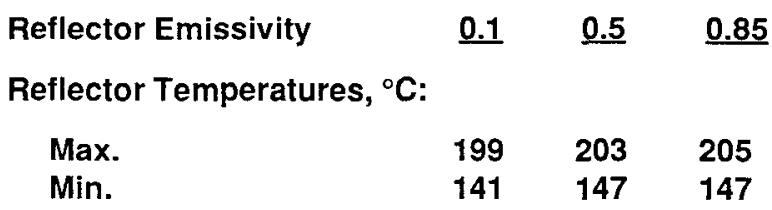

RTG Housing Temperatures, ${ }^{\circ} \mathrm{C}$ :

$\begin{array}{lrrr}\text { Max. } & 316 & 316 & 316 \\ \text { Min. } & 284 & 284 & 284 \\ \Delta T & 32 & 32 & 32\end{array}$

\section{ANALYSIS OF OBSTRUCTED RTGS}

The scoping-study results presented in Tables 2 through 4 permit only qualitative conclusions about the effect of the reflector on RTG power output. To obtain quantitative conclusions, a much more complex thermal and electrical analysis is needed.

Previous RTG analyses usually made the simplifying assumption that all of the thermoelectric couples in the generator's series-parallel network operate at the same hot-and cold-junction temperatures and at the same current and voltage. For unobstructed RTGs, such a simplified analysis is a useful initial design tool, since it permits closed-form solutions for the optimum area ratio $A_{n} / A_{p}$ of the thermoelectric $n$ - and $p$-legs and for the optimum output voltage. For these optimized parameters, it yields simple expressions for the maximum material efficiency of the thermoelectric couples, and for the required RTG design parameters $[5,6]$.

But the above simplifying assumptions can introduce significant errors even for unobstructed RTGs, because all RTGs have appreciable axial temperature variations due to unavoidable end losses by radiation and by conduction through the heat source support structure. A more exact analysis, which accounted for the axial temperature variations in a Martian RTG, was reported last year $[7,8]$. But that analysis still assumed that the RTG has an axisymmetric view of space and the Martian ground, and therefore no circumferential temperature variation. 
The present paper develops a Fairchildgenerated methodology and generalized computer code for analyzing the performance of arbitrarily obstructed RTGs with both axial and circumferential temperature, voltage, and current variations, and applies that methodology to the specific example of the Solar Probe RTG obstructed by a semi-cylindrical reflector of 15-inch radius.

\section{COUPLED THERMAL AND ELECTRICAL ANALYSIS}

Figure 9 presents the energy balance for a thermoelectric unicouple of leg length $L$, leg areas $A_{n}$ and $A_{p}$, operating between cold-and hot-junction temperatures $T_{1}$ and $T_{2}$. It gives the couple's thermal conductance $K$, electric resistance $R$, and open-circuit voltage $V_{0}$ in terms of the temperature-averaged thermal conductivity $\bar{k}$, electrical resistivity $\bar{\rho}$, and Seebeck coefficient $\bar{S}$ of the thermoelectric $n$ - and $p$ materials. As shown, the heat input rate $\boldsymbol{Q}_{h}$ at the couple's hot end and the heat rejection rate $Q_{c}$ at its cold end each consists of four terms: normal heat conduction, Peltier effect, Ohmic dissipation, and Thomson effect. As can be seen, three of those four terms are current-dependent. Therefore, the thermal and electrical analyses cannot be performed separately, but must be conducted simultaneously and interactively.

Figure 9. Unicouple Energy Balance

$$
\begin{array}{ll}
\text { Open-Circuit Voltage: } & V_{0}=\int\left(S_{n}+S_{p}\right) d T \\
\text { Couple Conductance: } & K=\left[\bar{k}_{n} A_{n}+\bar{k}_{p} A_{p}\right] / L \\
\text { Couple Resistance: } & R=\left[\bar{\rho}_{n} / A_{n}+\bar{\rho}_{p} / A_{p}\right] L
\end{array}
$$

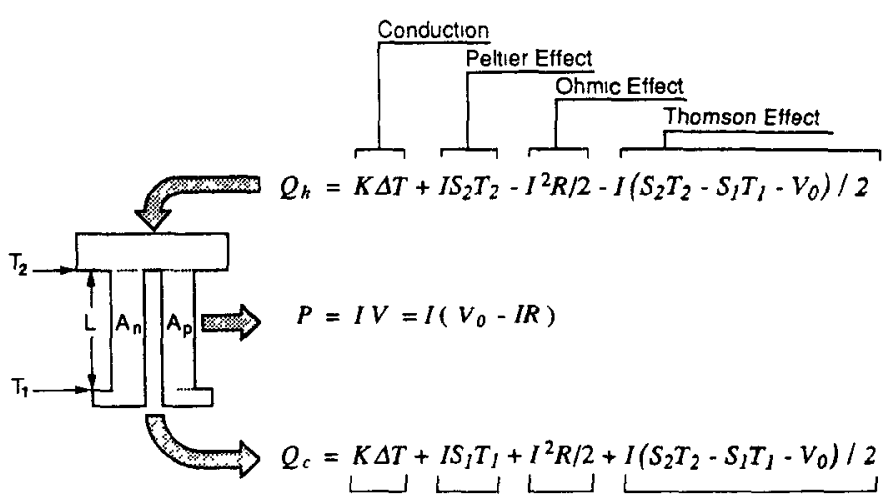

To analyze an RTG of a given design and an unsymmetrically obstructed heat rejection path, a detailed three-dimensional thermal model of the RTG and its environment must be constructed. The hot junction and cold junction of each thermoelectric element in the RTG are represented as discrete nodes.
The model cannot be analyzed by means of a standard thermal analysis code, because the connectors between the couple's hot and cold junctions are not simple thermal conductors but include the current-dependent Peltier, Ohmic, and Thomson effects. The rate at which heat enters the connector's hot end and leaves its cold end are not equal, since part of the heat entering each couple is converted to electrical energy. That part must be represented as an effective heat sink for each couple.

The electrical analysis is further complicated by the constraint that the RTG's thermoelectric couples are in general interconnected in a complex seriesparallel network, and that all couples grouped in parallel must operate at the same output voltage, and that all couple groups in series must produce the same current.

\section{RTG THERMOELECTRIC COUPLE NETWORK}

The series-parallel network of the GPHS-RTG is shown in Figure 10, which depicts a rolled-out schematic of the cylindrical array. The electrical network consists of two parallel branches. Each branch contains 144 series-connected groups of two parallel couples. The rather tortuous current path shown is designed to minimize the RTG's self-induced magnetic field.

Figure 10. Current-Path Through GPHS RTG

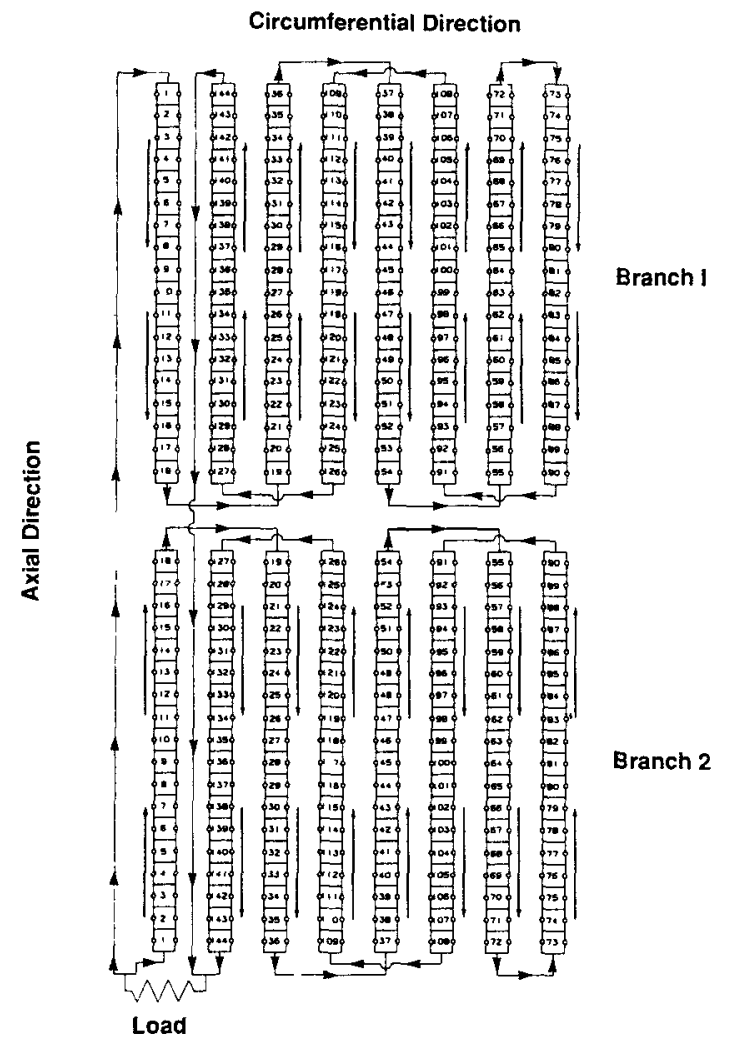


The RTG analysis methodology developed by Fairchild is generic, not just for the GPHS-RTG. In general, the equivalent circuit of an RTG network consists of $B$ parallel branches, with each branch containing $\mathrm{G}$ series-connected groups of $\mathrm{C}$ parallel couples. Each thermoelectric element in the RTG is designated by a branch number $b$, group number $g$, and couple number $\mathrm{c}$, where:

$$
\begin{aligned}
& 1 \leq b \leq B, \\
& 1 \leq g \leq G, \\
& 1 \leq C \leq C .
\end{aligned}
$$

For the case of the GPHS-RTG, $B=2, G=144, C=2$, and the equivalent circuit of the generator is shown in Figure 11.

Figure 11. Equivalent Circuit of GPHS RTG

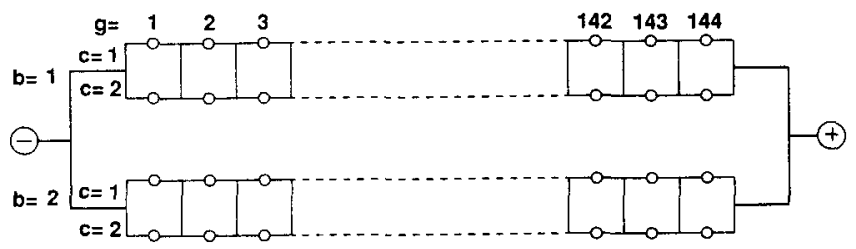

\section{ELECTRICAL ANALYSIS}

For each couple in the RTG, the difference between its open-circuit voltage $V_{0}(b, g, c)$ and its internal voltage drop $\mathbf{l}(\mathbf{b}, \mathbf{g}, \mathbf{c}) \mathbf{R}(\mathbf{b}, \mathbf{g}, \mathbf{c})$ equals its output voltage $V(b, g, c)$. Since the couples in each group $\mathbf{b}, \mathbf{g}$ are connected in parallel, their output voltage must equal the group voltage $\mathrm{V}(\mathrm{b}, \mathrm{g})$.

$$
V_{0}(b, g, c)-I(b, g, c) R(b, g, c)=V(b, g, c)=V(b, g)
$$

Therefore, the current through couple b,g,c is:

$$
I(b, g, c)=\left[V_{0}(b, g, c) \cdot V(b, g)\right] / R(b, g, c) .
$$

The sum of each group's $C$ couple currents equals the group current $I(b, g)$. Since all groups in each branch $b$ are connected in series, this must equal the branch current I(b):

$$
\sum_{c=1}^{C}\left[V_{d}(b, g, c) / R(b, g, c)\right]-V(b, g) \sum_{c=1}^{C}[1 / R(b, g, c)]=I(b, g)=I(b)
$$

Therefore, the voltage produced by group $b, g$, is:

$$
V(b, g)=\left\{\sum_{c=1}^{C}\left[V_{0}(b, g, c) / R(b, g, c)\right]-I(b)\right\} / \sum_{c=1}^{C}[1 / R(b, g, c)]
$$

The sum of the $G$ group voltages in each branch equals the branch voltage $V(b)$. Since the $B$ branches are connected in parallel, this also equals the RTG's output voltage $\mathbf{V}_{\mathbf{R T G}}$ :

$$
\sum_{g=I}^{G}\left\{\sum_{c=1}^{C}\left[V_{0}(b, g, c) / R(b, g, c)\right] / \sum_{c=1}^{C}[1 / R(b, g, c)]\right\}-I(b) \sum_{g=1}^{G}\left\{1 / \sum_{c=1}^{C}[1 / R(b, g, c)]\right\}=V(b)=V_{R T G} .
$$

Solving for the branch current $\mathrm{I}(\mathrm{b})$ for each branch and summing the currents for the B parallel branches gives the RTG output current:

$$
I_{R T G}=\sum_{b=1}^{B}\left\{\left[\sum_{g=1}^{G}\left\{\sum_{c=1}^{C}\left[V_{0}(b, g, c) / R(b, g, c)\right] / \sum_{c=1}^{C}[1 / R(b, g, c)]\right\}-V_{R T G}\right] / \sum_{g=1}^{G}\left\{1 / \sum_{c=1}^{C}[1 / R(b, g, c)]\right\}\right\} .
$$

The above equation represents the current-voltage characteristic of the RTG network. It can be expressed in the condensed form

$$
I_{R T G}=I_{S C}-V_{R T G} / R_{R T G},
$$

where $\mathrm{I}_{\mathbf{S C}}$ is the RTG's short-circuit current, defined by

$$
I_{S C}=\sum_{b=1}^{B}\left[\sum_{g=1}^{G}\left\{\sum_{c=1}^{C}\left[V_{0}(b, g, c) / R(b, g, c)\right] / \sum_{c=1}^{C}[1 / R(b, g, c)]\right\} / \sum_{g=1}^{G}\left\{1 / \sum_{c=1}^{C}[1 / R(b, g, c)]\right\}\right],
$$

and $\mathbf{R}_{\mathbf{R T G}}$ is the RTG's internal resistance, defined by

$$
R_{R T G}=1 / \sum_{b=1}^{B}\left[1 / \sum_{g=1}^{G}\left\{1 / \sum_{c=1}^{C}[1 / R(b, g, c)]\right\}\right] \text {. }
$$




\section{ITERATIVE COMPUTATIONS}

For each iteration in the analysis, the code uses each couple's cold- and hot-junction temperatures $T_{1}$ and $T_{2}$ (from the preceding iteration) to compute its temperature-averaged properties $\bar{k}$ and $\bar{\rho}$, open-circuit voltage $V_{0}$, thermal conductance $K$ and electrical resistance $R$ :

$$
\begin{aligned}
& \bar{k}_{n}(b, g, c)=\int_{T_{J^{(b, g, c)}}}^{T_{2(b, g, c)}} k_{n}(T) d T /\left[T_{2}(b, g, c)-T_{1}(b, g, c)\right] \\
& \bar{k}_{p}(b, g, c)=\int_{T_{1(b, g, c)}}^{T_{2(b, g, c)}} k_{p}(T) d T /\left[T_{2}(b, g, c)-T_{1}(b, g, c)\right] \\
& \bar{\rho}_{n}(b, g, c)=\int_{T_{J^{\prime}(b, g, c)}}^{T_{2}(b, g, c)} \rho_{n}(T) k_{n}(T) d T / \bar{k}_{n}(b, g, c)\left[T_{2}(b, g, c)-T_{1}(b, g, c)\right] \\
& \bar{\rho}_{p}(b, g, c)=\int_{T_{J^{(}(b, g, c)}}^{T_{2(b, g, c)}} \rho_{p}(T) k_{p}(T) d T / \bar{k}_{p}(b, g, c)\left[T_{2}(b, g, c)-T_{1}(b, g, c)\right] \\
& V_{0}(b, g, c)=\int_{T_{I^{(b, g, c)}}}^{T_{2^{(b, g, c)}}}\left[S_{n}(T)+S_{p}(T)\right] d T \\
& K(b, g, c)=\left[\bar{k}_{n}(b, g, c) A_{n}+\bar{k}_{p}(b, g, c) A_{p}\right] / L \\
& R(b, g, c)=\left[\bar{\rho}_{n}(b, g, c) / A_{n}+\bar{\rho}_{p}(b, g, c) / A_{p}\right] L
\end{aligned}
$$

Using these values of $V_{0}, K$, and $R$ for each couple and the prescribed $R T G$ voltage $V_{R T G}$, the code computes the branch current $I(b)$ for each of the $B$ branches,

$$
I(b)=\left[\sum_{g=1}^{G}\left\{\sum_{c=1}^{C}\left[V_{0}(b, g, c) / R(b, g, c)\right] / \sum_{c=I}^{C}[1 / R(b, g, c)]\right\}-V_{R T G}\right] / \sum_{g=1}^{G}\left\{1 / \sum_{c=1}^{C}[1 / R(b, g, c)]\right\},
$$

the group voltage $V(b, g)$ for each of the $G$ groups in each branch,

$$
V(b, g)=\left\{\sum_{c=1}^{C}\left[V_{0}(b, g, c) / R(b, g, c)\right]-I(b)\right\} / \sum_{c=1}^{C}[1 / R(b, g, c)],
$$

and the couple current $l(b, g, c)$ for each couple in the RTG,

$$
I(b, g, c)=\left[V_{0}(b, g, c)-V(b, g)\right] / R(b, g, c) .
$$

The individual couple currents are then used to compute the hot-end heat input rate $Q_{H}(b, g, c$,$) and the cold-end$ heat rejection rate $Q_{c}(b, g, c)$ for each couple:

$$
\begin{aligned}
Q_{H}(b, g, c) & =K(b, g, c)\left[T_{2}(b, g, c)-T_{1}(b, g, c)\right]-I^{2}(b, g, c) R(b, g, c) / 2 \\
& +I(b, g, c)\left[S_{2}(b, g, c) T_{2}(b, g, c)+S_{1}(b, g, c) T_{1}(b, g, c)+V(b, g, c)\right] / 2, \\
Q_{C}(b, g, c) & =K(b, g, c)\left[T_{2}(b, g, c)-T_{1}(b, g, c)\right]+I^{2}(b, g, c) R(b, g, c) / 2 \\
& +I(b, g, c)\left[S_{2}(b, g, c) T_{2}(b, g, c)+S_{1}(b, g, c) T_{1}(b, g, c)-V o(b, g, c)\right] / 2,
\end{aligned}
$$

where $S_{1}$ and $S_{2}$ denote the Seebeck coefficients at the cold- and hot-junction of the couple.

The code inserts these heat flow rates for each couple in the RTG into the detailed thermal analysis model for the next iteration; and repeats the procedure until convergence is achieved. 


\section{CODE VALIDATION}

The code was first tested in the analyses of an unobstructed generator, with axial temperature variation but no circumferential variation. It was validated by using it to analyze the performance of the electrically heated thermoelectric generator (ETG) that had been employed as the engineering test unit, a prototype of the GPHS-RTGs used for the Galileo mission [9]. The reason for using the ETG instead of the RTG as a validation check for the code is that the ETG test measurements include the thermocouples' hot-shoe temperatures, but - because of practical difficulties - the RTG measurements do not.

The analysis of the ETG's performance was based on thermoelectric properties of SiGe aged for one year to account for pre-test outgassing and processing. The temperature-dependent values of resistivity, conductivity, and Seebeck coefficient of the $\mathrm{n}$ - and $\mathrm{p}$-material are summarized in Table 5.

Table 5. Thermoelectric Properties Model

\begin{tabular}{|c|c|c|c|c|c|c|}
\hline $\begin{array}{l}\text { Temp } \\
{ }^{\circ} \mathrm{C}\end{array}$ & $\begin{array}{r}\mathrm{Se} \\
\mu\end{array}$ & $\mathrm{ck}$ & $\begin{array}{r}\text { Resist } \\
\mathrm{m} \Omega\end{array}$ & $\begin{array}{l}\text { ivity } \\
\text { cm }\end{array}$ & $\begin{array}{r}\text { Condu } \\
\mathrm{mW}\end{array}$ & $\begin{array}{l}\text { ivity } \\
\mathrm{cm} . \mathrm{K}\end{array}$ \\
\hline & $\mathrm{N}$ & P & $N$ & $\mathrm{P}$ & N & $\mathrm{P}$ \\
\hline 0 & 90 & 114 & 0.79 & 0.91 & 51.4 & 58.4 \\
\hline 50 & 113 & 128 & 0.87 & 0.95 & 50.2 & 57.2 \\
\hline 100 & 135 & 140 & 0.95 & 1.01 & 49.0 & 56.3 \\
\hline 150 & 153 & 152 & 1.04 & 1.08 & 47.9 & 55.0 \\
\hline 200 & 168 & 163 & 1.13 & 1.15 & 46.8 & 54.1 \\
\hline 250 & 185 & 173 & 1.28 & 1.24 & 45.8 & 52.9 \\
\hline 300 & 215 & 183 & 1.72 & 1.32 & 44.7 & 51.7 \\
\hline 350 & 265 & 192 & 2.77 & 1.42 & 43.9 & 51.0 \\
\hline 400 & 304 & 202 & 3.81 & 1.53 & 43.1 & 49.9 \\
\hline 450 & 317 & 211 & 4.17 & 1.64 & 42.5 & 49.1 \\
\hline 500 & 317 & 220 & 4.02 & 1.74 & 41.8 & 48.2 \\
\hline 550 & 312 & 229 & 3.75 & 1.87 & 41.5 & 47.5 \\
\hline 600 & 306 & 240 & 3.46 & 2.06 & 41.0 & 46.8 \\
\hline 650 & 298 & 256 & 3.13 & 2.38 & 40.8 & 46.2 \\
\hline 700 & 289 & 287 & 2.82 & 2.98 & 40.6 & 45.7 \\
\hline 750 & 280 & 320 & 2.53 & 4.49 & 40.6 & 45.3 \\
\hline 800 & 273 & 331 & 2.28 & 4.76 & 40.7 & 45.2 \\
\hline 850 & 268 & 330 & 2.09 & 4.54 & 40.9 & 45.4 \\
\hline 900 & 264 & 323 & 1.95 & 4.17 & 41.4 & 46.0 \\
\hline 950 & 263 & 318 & 1.86 & 3.84 & 42.1 & 47.1 \\
\hline 1000 & 263 & 316 & 1.82 & 3.57 & 43.4 & 49.2 \\
\hline 1050 & 262 & 314 & 1.77 & 3.22 & 45.6 & 52.2 \\
\hline 1075 & 262 & 314 & 1.75 & 3.10 & 46.9 & 54.3 \\
\hline
\end{tabular}

The analytical results were compared with the ETG test measurements. For the same RTG thermal power and the same average cold-junction temperature, the experimental measurements and the analytical results produced by the code were in very good agreement. The average hot-junction temperatures agreed within $5^{\circ} \mathrm{C}$ (986 versus 981 ), and the electrical power outputs agreed within 1 watt $(296$ versus 297).
As a further check on the validity of the analytical model, it was used to compute the BOM performance of one of the Galileo flight RTGs (F4). For the same thermal power, it yielded an electrical output of 285.6 watts, compared to the measured output power of 287.7 watts in Earth orbit. This agreement is better than the estimated $1.2 \%$ telemetry error.

The good agreement between the analytical and experimental results for both the ETG and the RTG lends confidence to our use of the same model and assumptions for subsequent analyses of the initial RTG output at various thermal powers and external environments.

\section{ANALYSIS OF OBSTRUCTED SOLAR PROBE RTG}

The application of the code to the analysis of the obstructed Solar Probe RTG started with the construction of a 942-node radiation-interchange analysis model. The model represented the housing and fins of the GPHS-RTG pictured in Figure 2 and the 15 " semi-cylindrical reflector shown in Figure 8 . The ITAS (Integrated Thermal Analysis System) code [10], which accounts for the effect of mutual reflections, was used to compute over 65,000 radiation interchange factors between all surface nodes that are within each other's view.

The computed radiation interchange factors were then inserted into a detailed thermal and electrical analysis model consisting of 1332 node points. The thermal power of the 18 stacked-up heat source modules was adjusted to account for fuel decay during the anticipated interval between the fuel encapsulation and the beginning of the mission (BOM).

The coupled thermal and electrical analysis was carried out by means of the previously discussed computer code. The code was based on the SINDA thermal analysis program [11], modified by us to incorporate the current-dependent Peltier, Ohmic, and Thomson effects on thermocouple conductance and to represent the electrical power generation in each couple as an effective heat sink. The modified code computed each couple's heat input rate and heat rejection rate in each iteration, and inserted them into the thermal analysis for the next iteration. After the solution had homed in to prescribed convergence criteria, it was used to calculate the RTG's electrical output and efficiency.

To illustrate typical results, the converged BOM solution for a thermal power of 240 watts from each of the 18 heat source modules is summarized in Tables 6 through 9. The tables display the results for the flattened-out cylindrical array of 576 thermocouples in the RTG. 
Table 6 shows the axial and circumferential variation of the RTG's coldjunction temperatures. As can be seen these vary from $286^{\circ} \mathrm{C}$ for the least obstructed couple to $327^{\circ} \mathrm{C}$ for the most obstructed couple. The last column and last line of the table show the variation of the averaged cold-junction temperatures in the axial and circumferential directions, respectively. As shown, the average temperature is lowest near the ends of the RTG, and highest near the RTG's midplane. Circumferentially, the average temperature is lowest in Column 10, the outward-facing side of the RTG, and highest in Column 2, the RTG side facing the reflector.

Table 7 similarly shows the axial and circumferential variations of the baseline RTG's hot-junction temperatures. As can be seen, the couples' average hot-junction temperatures vary by $34^{\circ} \mathrm{C}$ in the axial direction, and show essentially no variation in the circumferential direction. Thus, the obstruction by the reflector affects only the cold-junction temperatures, and produces only a negligible circumferential variation of the hot-junction temperatures. In addition to the hot-junction temperatures, the table shows the axial variation of the heat source surface temperatures. As shown by the table's left column, these vary from $1014^{\circ} \mathrm{C}$ at the upper end of the heat source stack to $1046^{\circ} \mathrm{C}$ near the middle of the stack.

The consequent variation in the thermocouples' temperature-spans affects their electrical performance. The axial and circumferential variations of the couple voltages is displayed in Table $B$, and those of the couple currents in Table 9 . The sixteen columns in these tables represent eight column pairs of parallel couples. Table 8 shows that all parallel couples have the same output voltage, ranging from 0.195 volt to 0.219 volt; and Table 9 shows that all couple pairs in each branch have the same combined output current, as demanded by the RTG's series-parallel network.

As can be seen, the network's two branches have respective output currents of 4.95 and 4.98 amps, for a total RTG output of 9.93 amps. The 144 seriesconnected couple groups in each branch produced 30.0 volts. Subtracting 0.34 volts for ohmic losses in the RTG's series leads leaves a net output of 29.66 volts and 295 watts. The average material efficiency of the couples is $7.77 \%$; the average couple efficiency (including the effect of contact resistances and electrode losses) is $7.44 \%$; and the net system efficiency (including the effect of heat losses through the thermal insulation and through the heat source support structure) is $6.88 \%$.
Table 6. Cold-Junction Temperatures $\left({ }^{\circ} \mathrm{C}\right)$

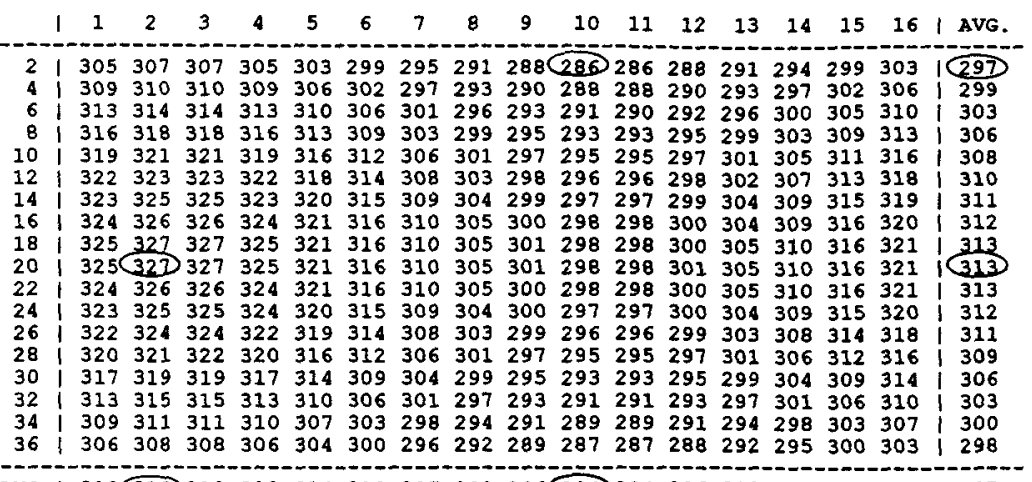

AVG | 318 (319) $319318 \quad 314 \quad 310 \quad 305 \quad 300 \quad 296(294) 294 \quad 296300 \quad 304310 \quad 314 \mid 307$

Table 7. Hot-Junction Temperatures $\left({ }^{\circ} \mathrm{C}\right)$

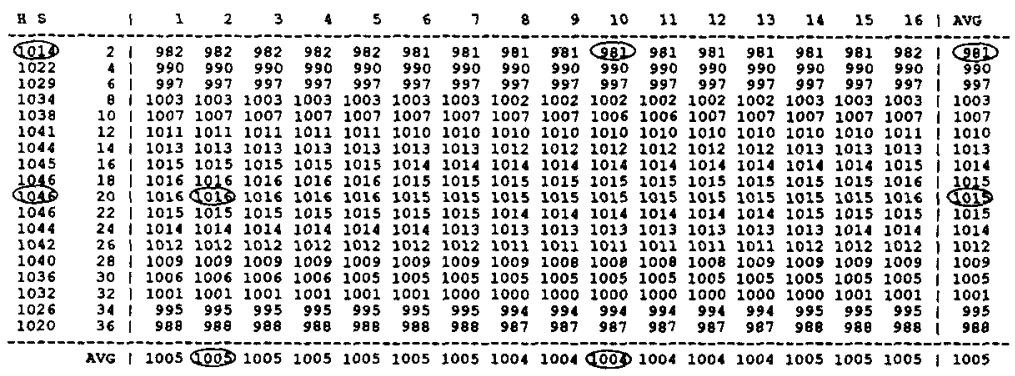

Table 8. Couple Voltage ( $\mathrm{mV})$

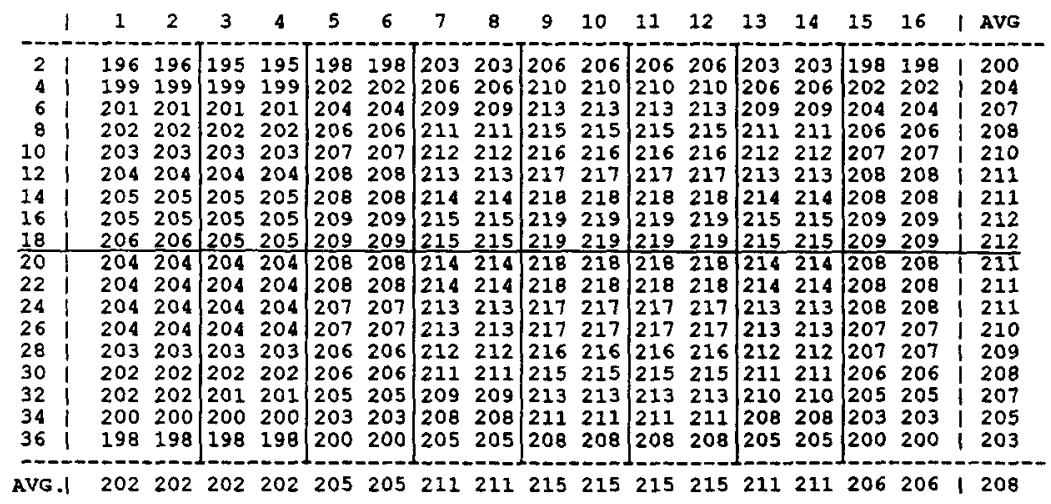

Table 9. Couple Current (amp)

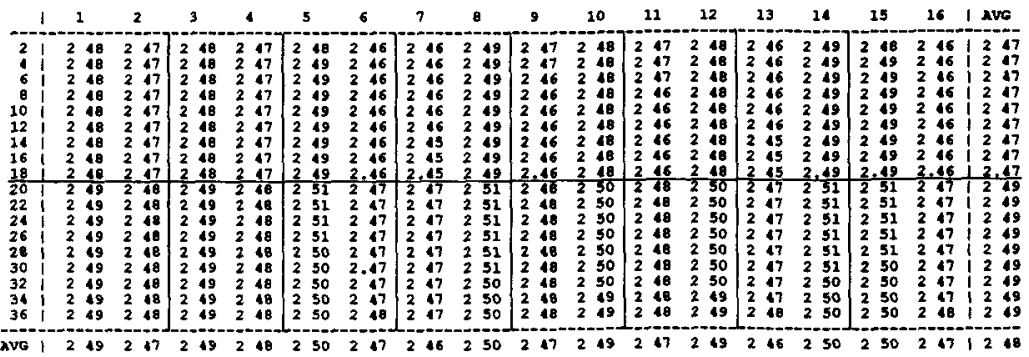


Equally detailed coupled thermal and electrical analyses were performed for thermal power levels ranging from 225 to 250 watts per heat source module, for both obstructed and unobstructed RTGs. The principal results for an RTG obstructed by a 15"-radius reflector and the comparative results for an unobstructed RTG are displayed in Figures 12 and 13. The unobstructed units had axial temperature variations but no circumferential variation.

Figures 12 and 13 respectively show the effect of the thermal power $Q$ per heat source module on the RTG power output and on the average hot-junction temperature. As can be seen, both relationships are essentially linear, and the figures present least-square curve fits for the respective curves. These curve fits are useful design tools, and will be used to predict the effect of fuel decay on RTG power and temperature. The two figures show that, for a given thermal power, the obstruction by the reflector has very little effect on the RTG's power output, but has a significant effect on its hot-junction temperature, which affects the degradation rate.

Figure 14 presents cross-plots showing the relationship between maximum hot-junction temperatures and BOM power outputs for unobstructed RTGs and for RTGs obstructed by reflectors of 10- and 15-inch radius.

The performance of the obstructed and unobstructed RTGs should be compared for the same maximum hot-junction temperature, since that is what determines the RTG's degradation rate and lifetime. Previous SiGe flight units (LES 8/9, Voyager, Galileo) were designed for a maximum hot-junction

Figure 12. Effect of Thermal Power on BOM Electrical Power

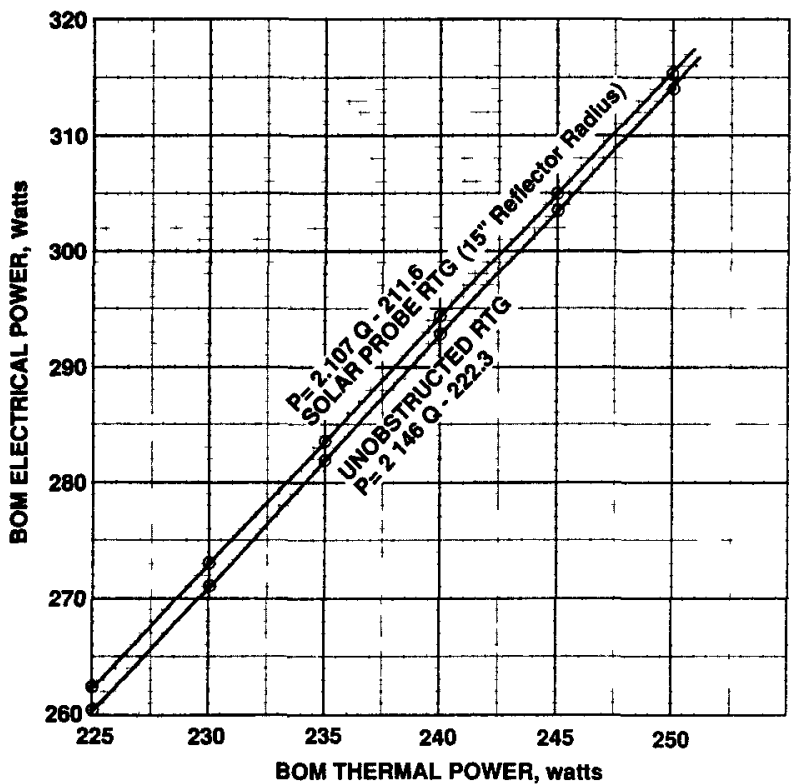

Figure 13. Effect of Thermal Power on Average Hot-Junction Temperature

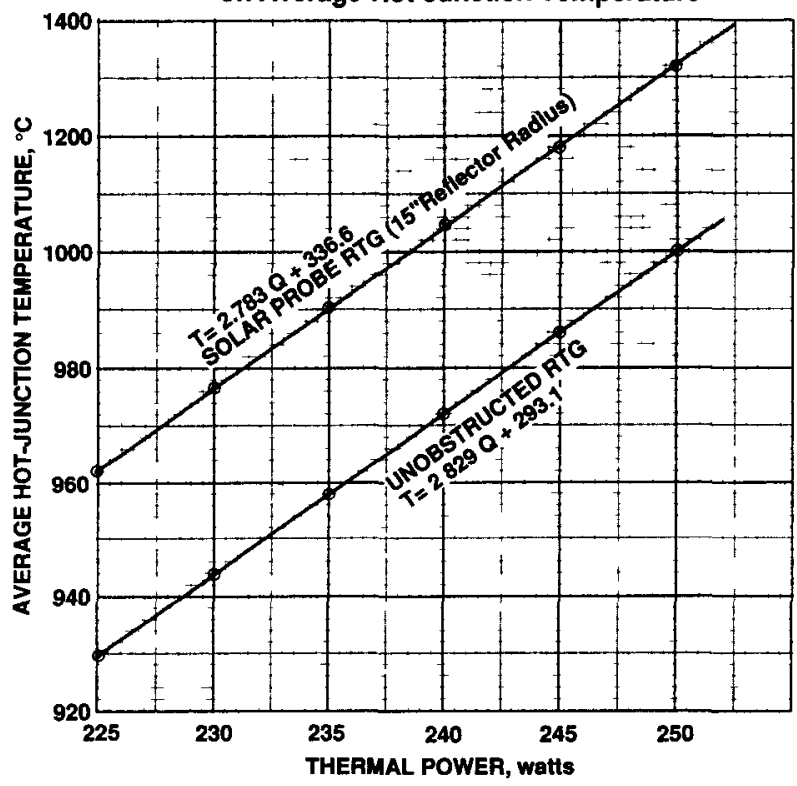

temperature of $1000^{\circ} \mathrm{C}$. For that temperature, Figure 14 shows that the RTG's power output is reduced by 23 watts $(7.5 \%)$ for the $15^{\text {n }}$ reflector, and by 52 watts $(17.0 \%)$ for the $10^{\prime \prime}$ reflector. This confirms the high sensitivity of power output to reflector radius, and shows that even a $15^{\prime \prime}$ radius results in a significant performance penalty for the standard GPHS-RTG design.

Figure 14. Effect of Reflector Radius on PowerVersus-Temperature Characteristics

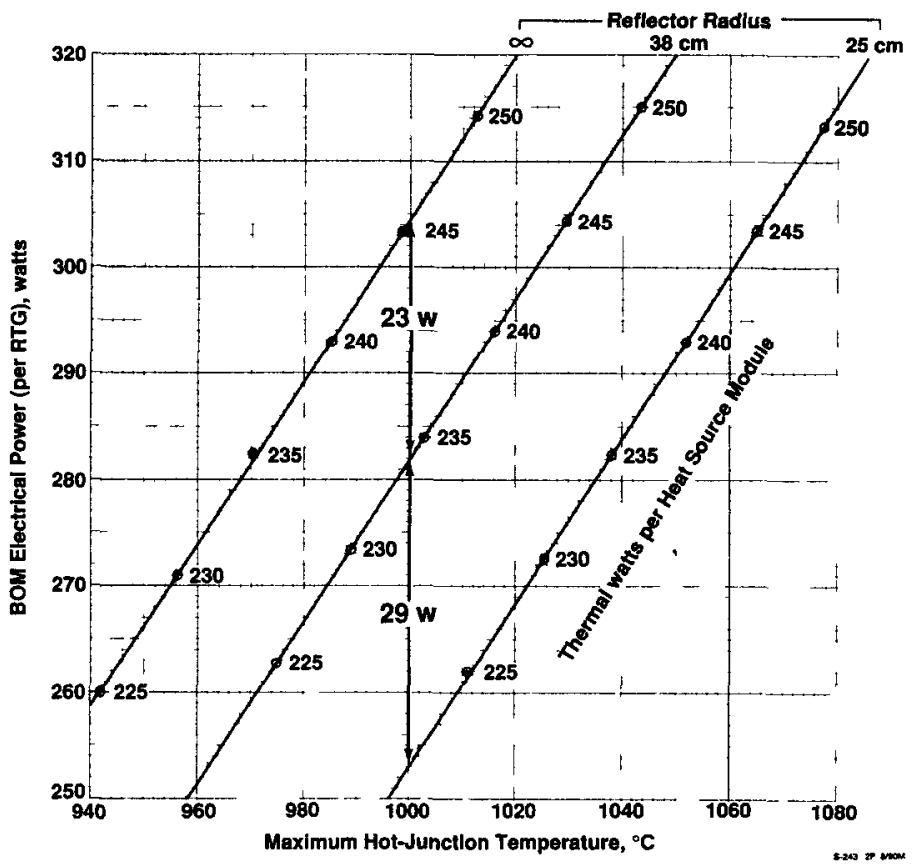




\section{LONG-TERM PERFORMANCE DEGRADATION}

In addition to BOM power, the system designer is of course interested in the RTGs' EOM power. The principal factors that diminish an RTG's power output with time are fuel decay and thermoelectric degradation.

Predicting the thermoelectric performance degradation with time is generally a complex problem, since many different degradation mechanisms are at play. A detailed method for making such predictions is the DEGRA code developed by $V$. Raag in the early 70's [13], but that code does not account for the detalled effects of mutual obstruction between neighboring RTGs. In the same time period, A. Mowery [14] performed statistical analyses of test results which showed that the degradation of power $\mathbf{P}$ with time $t$ of electrically heated thermoelectric converters employing SiGe unicouples at constant hotjunction temperatures $T$ can be quite accurately predicted by the simple empirical equation

$$
\begin{aligned}
& P / P_{1}=1-[a \exp (-b / 7)] \sqrt{t}, \\
& \text { where } a=6973 \text { yr-1/2 and } b=15480^{\circ} \mathrm{K} \text {. }
\end{aligned}
$$

This empirical expression was found to give excellent agreement with the experimental data from the electrically heated tests at various constant thermal powers and temperatures. However, Mowery's equations cannot be directly applied to predict the performance degradation of RTGs because an RTG operates at a diminishing thermal power and temperature, and therefore at diminishing degradation rates. To account for that effect, the present author developed the following simple modification of Mowery's original equation:

$$
P / P_{1}=1-\left\{\int_{0}^{t}\left[a \exp \left(-b / T\left(t^{\prime}\right)\right)\right]^{2} d t^{\prime}\right\}^{1 / 2}
$$

This modification appears quite plausible, but its validity must be confirmed by comparing its results to long-term tests with variable T. (Note that for the special case of constant $T$, the modified equation reduces to Mowery's validated equation.)

The effect of fuel decay on thermal power $Q$ per heat source module is given by

$$
Q=Q_{1} / 2^{t / \tau}
$$

where $Q_{1}$ is the $B O M$ thermal power

and $\tau$ is the isotope's half-life ( 87 years)

The effect of thermal power decay on the RTG's hotjunction temperature $\mathrm{T}$ and its undegraded power $\mathrm{Pu}_{\mathrm{u}}$ is given by the linear correlations

$$
T=a_{T}+b_{T} Q \text { and } P_{u}=a_{p}+b_{P} Q \text {, }
$$

where the coefficients $a_{T}, b_{T}, a_{p}$, and $b_{P}$ for the obstructed RTG are obtained from the computed results shown in Figures 12 and 13 . Thus, the combined effect of fuel decay and degradation on the power output of the obstructed RTG is given by

$P=\left(a_{P}+b_{P} a_{1} / 2^{t / \tau}\right)\left[1-a\left\{\int_{0}^{t} \exp \left[-2 b /\left(a_{T}+b_{T} a_{1} / 2^{t / \tau}\right)\right] d t^{\prime}\right\}^{1 / 2}\right]$

\section{VALIDATION OF DEGRADATION MODEL}

The above equations were applied to the Q-1 RTG, which was the qualification unit for the GPHSRTGs used on the Galileo mission. The computed results are shown in Figure 15. The curve labeled $Q / Q_{1}$ shows the thermal power decay, and the curve labeled $T$ shows the resultant decrease in average hotjunction temperature. The curve labeled $\mathbf{P}_{\mathbf{u}} / \mathbf{P}_{\mathbf{1}}$ shows the power loss due to fuel decay for undegraded thermoelectric performance, and the curve labeled $\mathbf{P} / \mathbf{P}_{\mathbf{u}}$ shows the power loss due to thermoelectric degradation. The combined effect of fuel decay and thermoelectric degradation is shown by the curve labeled $\mathbf{P} / \mathbf{P}_{\mathbf{1}}$. As can be seen, the combined effect is predicted to result in a $23.6 \%$ power loss in 12 years.

Figure 15. Effect of Fuel Decay and Thermoelectric Degradation on Performance of Galileo Qualification RTG $(Q-1)$

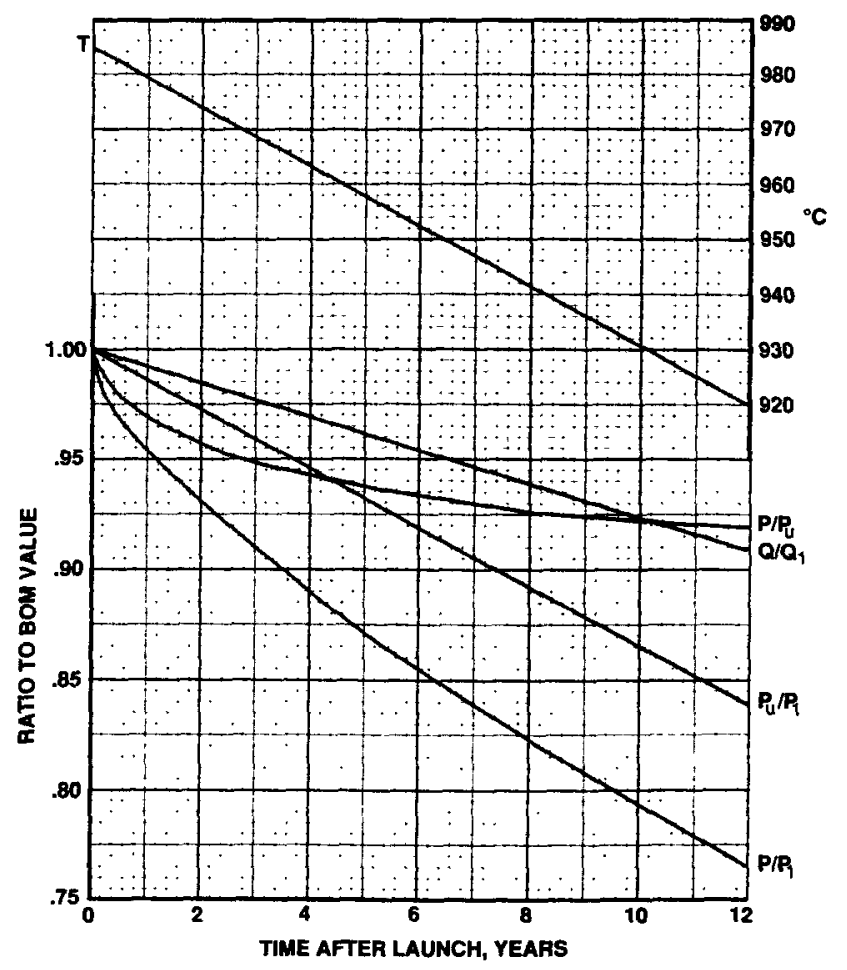


Figure 16 shows a comparison of these predictions with the measured results of a five-year test of the Q-1 RTG. As can be seen, for the range of times and temperatures tested, the rather simple prediction model used showed surprisingly good agreement with the experimental results.

Figure 16. Comparison of Predicted and Measured Power History of Q-1 FTG

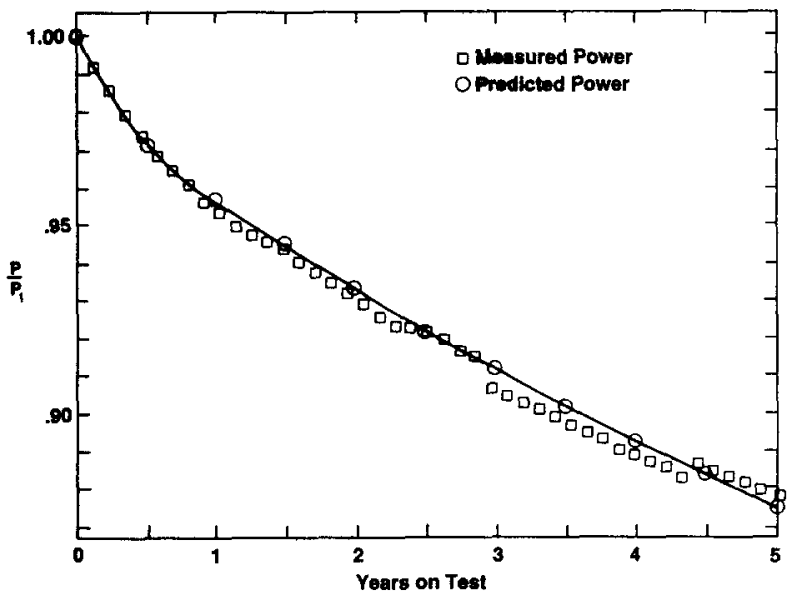

APPLICATION TO SOLAR PROBE RTGS

Finally, the analytical methodology described above was used to predict the long-term power degradation of the obstructed Solar Probe RTGs. The analytical results for the $15^{\mathrm{N}}$ reflector radius are shown in Figure 17, and those for the 10" radius are shown in Figure 18. For various initial thermal power levels, the figures show the variation of RTG power and average hot-junction temperature with time. Thus, the figure can be employed as a useful design tool by the Solar Probe mission planners.

The two figures show that increasing the BOM thermal power (by increasing the fuel loading) leads to substantial increase of the BOM electrical power, but to a diminishing benefit in increasing the RTG's EOM output, particularly for long mission times. This comes about because higher thermal powers result in higher temperatures and therefore higher degradation rates. In fact, at unrealistically high hot-junction temperatures $\left(>1100^{\circ} \mathrm{C}\right.$ ) increasing the thermal power can actually decrease the EOM electrical power.

The asterisk in each figure shows JPL's tentative design requirement, i.e., an electrical output of 430 watts at the end of mission. As can be seen from Figures 17 and 18 , that requirement can be met with a BOM thermal power (per heat source module) of 225 watts for the $15^{n}$ reflector and 230 watts for the $10^{n}$ reflector. The corresponding results for the two cases are summarized in Table 10, which shows the electrical powers, hot- and cold-junction temperatures, and efficiencies at the beginning of mission and at the first and second solar encounters. As can be seen, the hot-junction temperature for the 10"-radius reflector is almost $50^{\circ} \mathrm{C}$ higher than that for the $15^{\prime \prime}$ reflector.
Thus, while the BOM hot-junction temperature for the $15^{\prime \prime}$ reflector is $35^{\circ} \mathrm{C}$ below the previously used $1000^{\circ} \mathrm{C}$ design limit, it exceeds that limit by $13^{\circ} \mathrm{C}$ for the $10^{\prime \prime}$ reflector. The actual reflector radius used will be determined by the results of JPL's ongoing spacecraft design studies.

Figure 17. Effect of Fuel Loading on Power and Temperature History of Solar Probe RTG with 15"-Radius Reflector

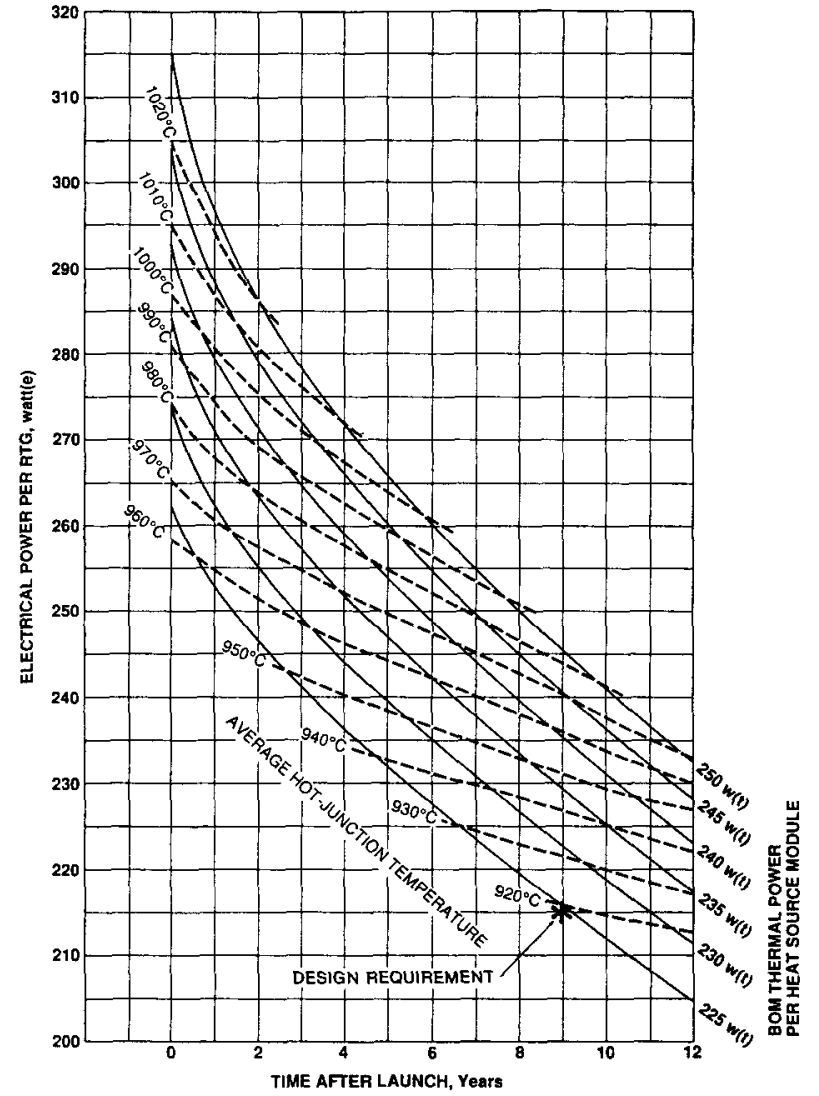

The maximum BOM thermal power depends on the available fuel density and enrichment, and on the time interval between fuel encapsulation and launch. A typical RTG (F1) on the recently launched Galileo mission had a thermal power of 251.8 watts per module at the time of fuel encapsulation in September

Table 10. Solar Probe RTG Performance Parameters

\begin{tabular}{|c|c|c|c|c|c|c|}
\hline \multirow{2}{*}{$\begin{array}{c}\text { Reflector Radius } \\
\text { Mission Time }\end{array}$} & \multicolumn{3}{|c|}{$15^{\prime \prime}$} & \multicolumn{3}{|c|}{$10^{\prime \prime}$} \\
\hline & BOM & \multicolumn{2}{|c|}{ Solar Encounter } & BOM & $\begin{array}{l}\text { Solar Er } \\
1 \text { st }\end{array}$ & and \\
\hline Thermal Power, Watts (t) & & & & & & \\
\hline $\begin{array}{l}\text { Per Heat Source Module } \\
\text { Per RTG }\end{array}$ & $\begin{array}{r}225 \\
4050\end{array}$ & $\begin{array}{r}216 \\
3888\end{array}$ & $\begin{array}{r}209 \\
3769\end{array}$ & $\begin{array}{r}230 \\
4140\end{array}$ & $\begin{array}{r}221 \\
3978\end{array}$ & $\begin{array}{r}214 \\
3854\end{array}$ \\
\hline \multicolumn{7}{|l|}{ Temperature, ${ }^{\circ} \mathrm{C}$} \\
\hline $\begin{array}{l}\text { Hot - junction } \\
\text { Cold-junction }\end{array}$ & $\begin{array}{l}962 \\
296\end{array}$ & $\begin{array}{l}939 \\
290\end{array}$ & $\begin{array}{l}920 \\
285\end{array}$ & $\begin{array}{c}1013^{*} \\
341\end{array}$ & $\begin{array}{l}988 \\
334\end{array}$ & $\begin{array}{l}970 \\
329\end{array}$ \\
\hline \multicolumn{7}{|l|}{ Electrical Power, Watts (e) } \\
\hline $\begin{array}{l}\text { Per RTG } \\
\text { Two RTGs }\end{array}$ & $\begin{array}{l}262 \\
524\end{array}$ & $\begin{array}{l}231 \\
462\end{array}$ & $\begin{array}{l}215 \\
430\end{array}$ & $\begin{array}{l}272 \\
544\end{array}$ & $\begin{array}{l}233 \\
466\end{array}$ & $\begin{array}{l}215 \\
430\end{array}$ \\
\hline \multicolumn{7}{|l|}{ Efficiency, \% } \\
\hline $\begin{array}{l}\text { Material } \\
\text { RTG }\end{array}$ & $\begin{array}{l}7.41 \\
6.47\end{array}$ & $\begin{array}{l}7.21 \\
5.94\end{array}$ & $\begin{array}{l}7.04 \\
5.70\end{array}$ & $\begin{array}{l}7.52 \\
6.57\end{array}$ & $\begin{array}{l}7.31 \\
5.86\end{array}$ & $\begin{array}{l}7.16 \\
5.58\end{array}$ \\
\hline
\end{tabular}


1982. Had it been launched in May 1986, as planned, that would have decayed to 246.5 watts $(t)$ at the beginning of mission. However, the actual launch of Galileo was delayed to October 1989 , to provide time for Shuttle modifications after the Challenger accident. Therefore, the Galileo RTGs had a thermal power of 238 watts at $\mathrm{BOM}$.

Thus, even with these unusual delays, the BOM thermal power was still much in excess of the 225 or 230 watts per heat source module required to meet the Solar probe's present EOM power goal with the current RTG design. In addition, design improvements to reduce the required fuel loading and RTG mass are possible and should be explored.

\section{ACKNOWLEDGEMENT}

The author is pleased to acknowledge the support and encouragement of DOE's Office of Special Applications (J. Turi, Director) and of JPL's Solar Probe Team (J. Randolph, Manager).

\section{REFERENCES}

[1] Feldman, William, Chairman, 1989 Solar Probe Sclence Study Team, "Solar Probe Scientific Rationale and Mission Concept," JPL-D-6797, Jet Propulsion Laboratory, November 1989.

[2a] Schock, A., and H. Sookiazian (1979) "Conceptual Design of the RTG for Solar Polar Mission," \#799307. Presented at the 14th Intersociety Energy Conversion Engineering Conference, held in Boston, Massachusetts, August 1979.

[2b] Cockfield, R.D., R.F. Hartman, C.D. Kelly (1980) "RTG Power Sources for international Solar Polar Mission," Proc. of the 15th Intersociety Energy Conversion Engineering Conference, held in Seattle, Washington, 1980.

[2c] Cockfield, R.D. (1986) "Qualification of GPHS-RTG for Gallieo and Ulysses," Proc. of the 21 st Intersociety Energy Conversion Engineering Conference, held in San Diego, California, 1986

[3] Schock, A. (1981) "Modular Isotopic Thermoelectric Generator," Vol. 1, pages 327-342. Proc, of the 16th Intersociety Energy Conversion Engineering Conference, heid in Atlanta, Georgia August 1981.

[4] Schock, A. (1980) "Design Evolution and Verification of the General Purpose Heat Source, " Vol. 2, pages 1032-1042. Proc. of the 15th Intersociety Energy Conversion Engineering Conference, held in Seattle, Washington, 1980.

[5] lotfe, A.F. (1957) Semiconductor Thermoelements and Thermoelectric Cooling, Infosearch, London, 1957.

[6] Schock, A., et al. (1989) "Mars Rover RTG Study," FSC-ESD217/89/450A. Fairchild Space Company, Germantown, MD November 1989.

[7] Schock, A., C.T. Or, and E.A. Skrabek (1990) "Thermal and Electrical Analysis of Mars Rover RTGs, and Performance Comparison of Alternative Design Options," Trans. of the Seventh Symposium on Space Nuclear Power Systems, held in Albuquerque, New Mexico, January 1990.

[8] Schock, A., T. Hamrick, and K. Sankarankandath (1990) "Design and Structural Analysis of Mars Rover RTG," in Trans. of the Seventh Symposium on Space Nuclear Power Systems, held in Albuquerque, New Mexico, January 1990.
Figure 18. Effect of Fuel Loading on Power and Temperature History of Solar Probe RTG with 10"-Radius Reflector

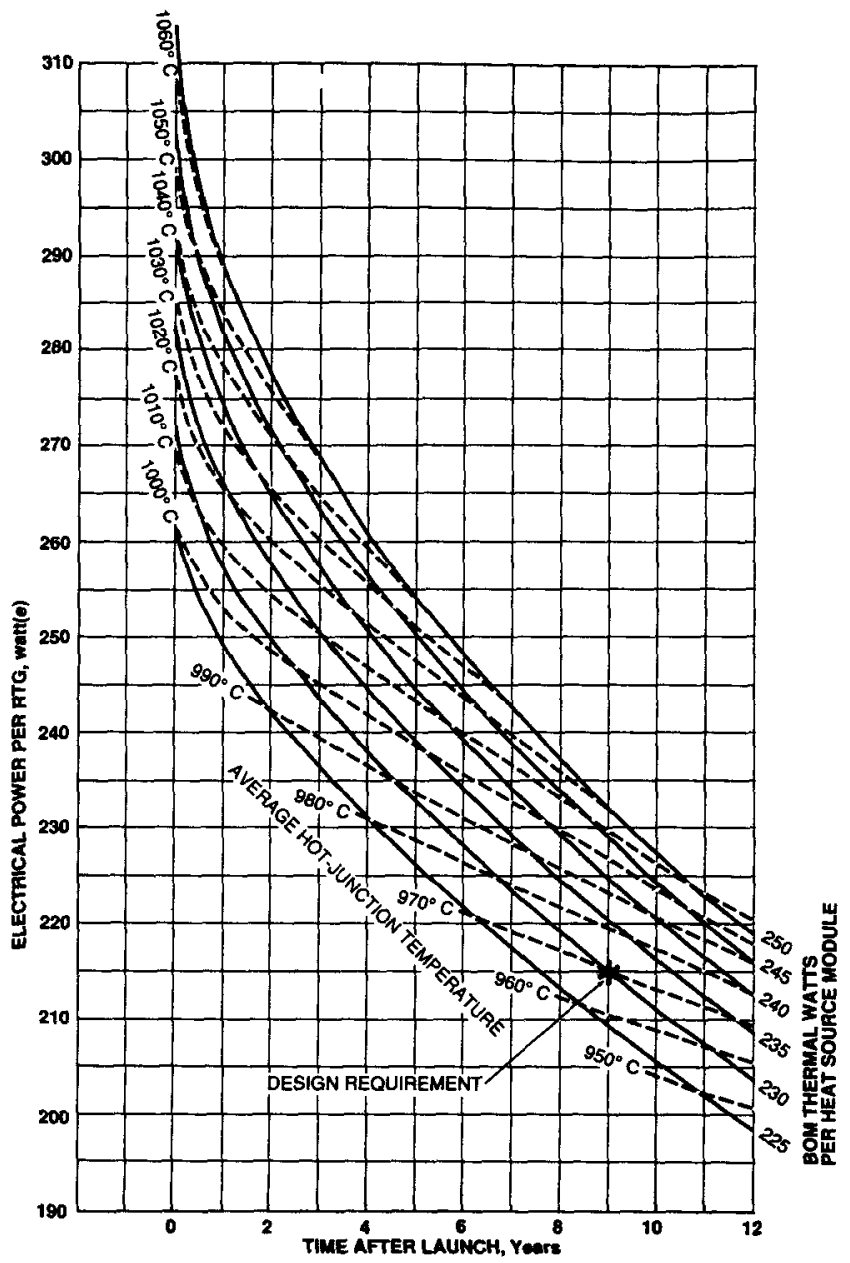

[9] Loffreda, J. (1982) "Engineering Unit Test Results," PIR-6377. General Electric, Space Division, Philadelphia, PA, May 1882.

[10] ITAS: Integrated Thermal Analysis Systems, Analytix Corporation Timonium, Maryland, 1990.

[11] Gaskl, J. (1986) SINDA (System Improved Numerical Differencing Analyzer) version 1.23 trom Network Analysis Associate, Fountain Valley, Celliornie.

[12] Raag, V. and K.P. McCarron (1973) "Mathematical Model and Computer Program for the Design and Analysis of SiliconGermanium Air-Vac RTG Degradation," Memorandum *15. Syncal Corporation, Sunnyvale, Callfornia, October 1973.

[13] Mowery, A.L. (1975) "Preliminary Power Degradation Report," Interoffice Memorandum to J. Lombardo, U.S. Energy Research and Development Administration, Washington, D.C. May 1975. 